Document downloaded from:

http://hdl.handle.net/10251/79380

This paper must be cited as:

López-Paz, JL.; Catalá-Icardo, M. (2008). Flow injection-photoinduced-chemiluminescence determination of ziram and zineb. Analytica Chimica Acta. 625(2):173-179. doi:10.1016/j.aca.2008.07.027.

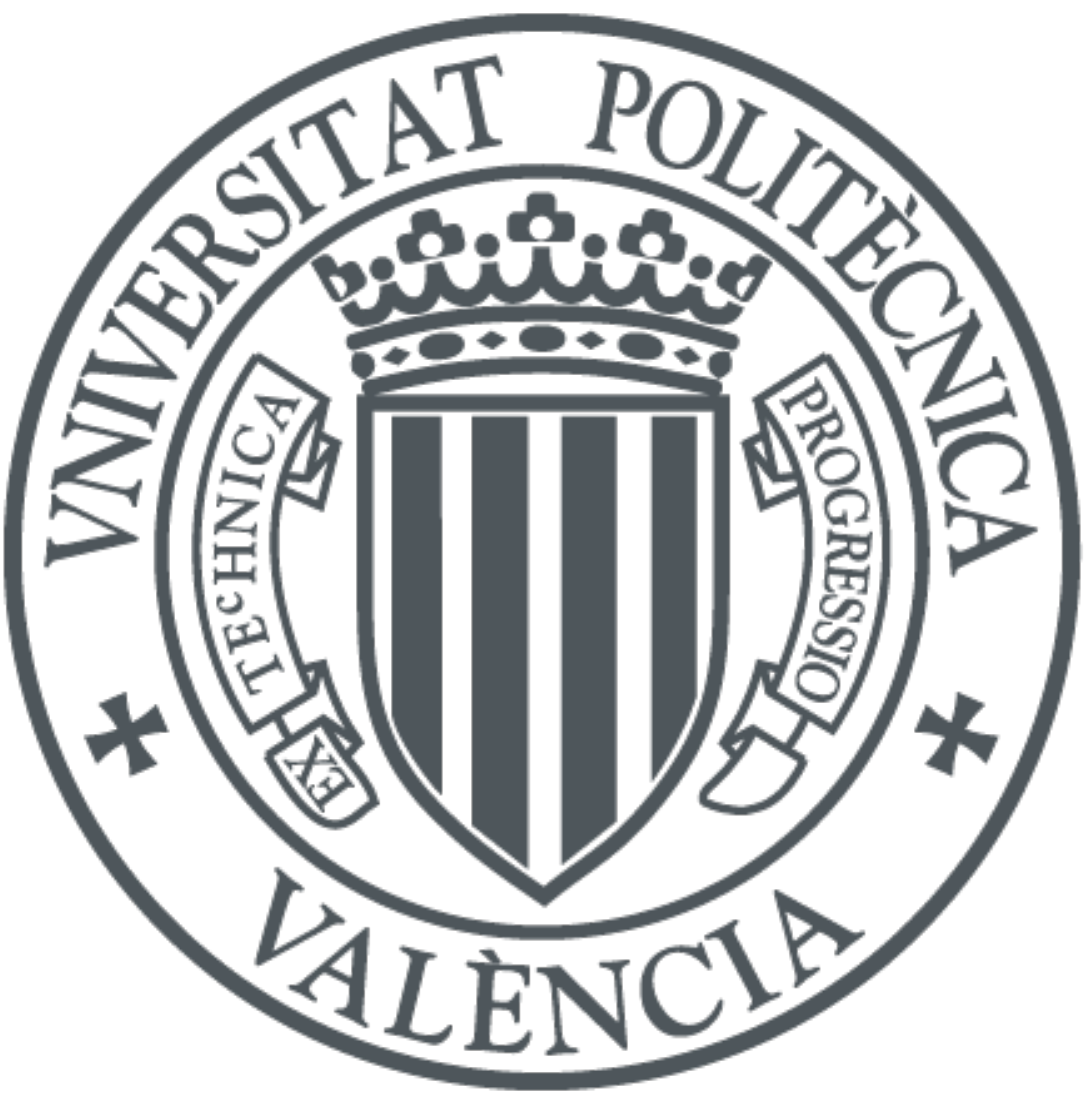

The final publication is available at

http://dx.doi.org/10.1016/j.aca.2008.07.027

Copyright Elsevier Masson

Additional Information 


\title{
FLOW INJECTION-PHOTOINDUCED-CHEMILUMINESCENCE DETERMINATION OF ZIRAM AND ZINEB.
}

\author{
J.L. López Paz ${ }^{\text {a* }}$ and M. Catalá-Icardo ${ }^{\text {a }}$. \\ * Corresponding author.Tel: ++34963877815; fax: ++34963877809. \\ E-mail address: jolopa@qim.upv.es \\ ${ }^{a}$ Integrated Coastal Management Research Institute. Higher Polytechnic School of Gandia. \\ Polytechnic University of Valencia.
}

\section{ABSTRACT}

A simple, sensitive and rapid method for the determination of the pesticides ziram and zineb was described. This new method was based on the coupling of FIA methodology and direct chemiluminescent detection; this approach had not been used up to now with these pesticides. The additional use of an 'on line' photochemical reaction, which was performed by using a photoreactor consisting of a long piece of PTFE helically coiled around a $15 \mathrm{~W}$ low-pressure lamp, increased by a factor $>20$ the chemiluminometric response of the pesticides. An additional 3 fold improvement in the analytical signal was also achieved by using quinine as sensitizer. The obtained throughputs were very high (121 and $101 \mathrm{~h}^{-1}$ for ziram and zineb respectively); this feature together with its low limit of detection $\left(1 \mathrm{ng} \mathrm{mL} \mathrm{m}^{-1}\right)$ makes this method particularly well suited to routine analyses of environmental samples. On the other hand, its applicability to two members of the dithiocarbamate family of pesticides, makes it promising for the determination of the rest of the members of this family. The method was demonstrated by application to spiked water samples from different origins (ground, river and irrigation).

Author Keywords: Chemiluminescence; flow injection; ziram; zineb; photochemical.

\section{Introduction}

Ziram [Zinc bis (dimethyldithiocarbamate)] and zineb [Zinc ethylene-1,2-bisdithiocarbamate)] (molecular structures in figure 1) are broad spectrum fungicides. They are mainly used to prevent crops damage in the field and during their storage or transport because of its low phytoxicity. Ziram is also formulated into a bird and rodent repellents and registered for use as an industrial preservative in exterior latex paints, adhesives, caulking and sealants; zineb is also used in 
antifouling products. Both belong to the dithiocarbamate group of fungicides which have replaced most of organochlorine pesticides. They have neuropathy as a common toxic effect and direct exposure to them can also cause allergy to skin and inflammation of eyes and respiratory tract in humans ${ }^{1}$. Despite of the acute toxicity for these compounds is low, they were found to be carcinogenic in a pathological study ${ }^{2}$. On the other hand, they can form strong complexes with trace elements such as $\mathrm{Cu}$ (II) when are released into the environment; these complexes have been shown to increase trace uptake by aquatic organisms. Moreover, there is growing concern about the potential estrogenic effects and chronic toxicity of these compounds on other animal species ${ }^{3}$.
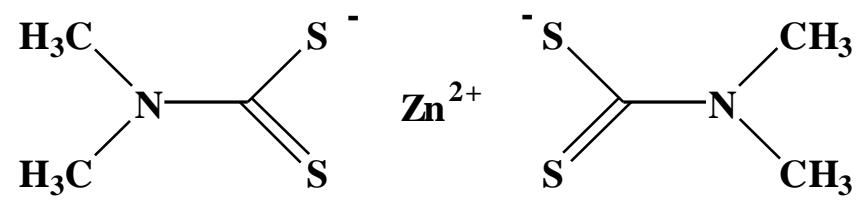

Ziram

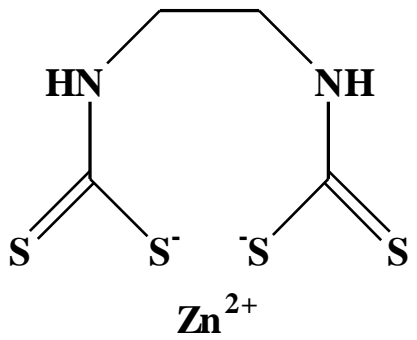

Zineb

Figure 1. Molecular structures of ziram and zineb

The standard procedure recommended for these substances by the AOAC (Official Methods of Analysis) involves the production of $\mathrm{CS}_{2}$ by acid hydrolysis, which is absorbed in a methanolic potassium hydroxide solution; the xanthate so formed is then titrated iodimetrically ${ }^{4}$. This method has drawbacks associated with the detection of end point with starch, the production of $\mathrm{H}_{2} \mathrm{~S}$ from sulfide impurities and the hydrolitic decomposition of xanthate solutions.

Many of the recent analytical methods developed up to now for the determination of ziram are spectrophotometric ${ }^{5-9}$, but they are time consuming and their sensitivity is low. Gas chromatographic (GC) methods are commonly used for pesticide analysis, but ziram is a nonvolatile compound, hence it would not be suitable for direct detection by these methods. Because of this, the GC methods developed for ziram determination are based on detection of $\mathrm{CS}_{2}{ }^{10,11}$. Some liquid chromatographic (LC) ${ }^{12-16}$ methods have been also developed for analysis of pesticides but, despite of its selectivity, they are expensive and involve the use of toxic and expensive solvents. Particularly remarkable, bearing in mind the high number of tested pesticides, is the LC method developed by K.Yu et al. ${ }^{17}$. These authors were able to analyse 46 analytes out of 52 targets by using a mass spectroscopy detector, however ziram was one of the six for which no result was obtained and zineb was not tested. Other alternative analytical methods such as atomic absorption spectroscopy ${ }^{6,18-20}$, capillary electrophoresis ${ }^{21}$ and amperometry ${ }^{22}$ have been also developed but they are less sensitive than the CL-FIA method herein reported. Moreover some of them require 
extraction with organic solvents, which is sometimes tedious, time-consuming and prone to errors due to incomplete extraction.

The increasing use of carbamate pesticides have resulted in demands for the development of sensitive and rapid analytical methods. These features are accomplished by the coupling of chemilumenescent (CL) detection and flow injection (FIA) methods. CL systems provide high sensitivities and wide dynamic ranges. On the other hand, FIA techniques allow the rapid and reproducible mixing of sample and reagent near the detector, which makes this methodology particularly well suited to monitoring transient light emission from CL reactions. In addition, the use of light from a low-pressure lamp provides a clean, reproducible and inexpensive "reagent", which offers a powerful means for obtaining derivatives with improved features for analytical methods involving CL-detection. However, although there are many analytical methods for the determination of dithiocarbamate fungicides, to the authors knowledge up to now no method based on CL-photodegradation for ziram and/or zineb has been previously reported. Only one method based on CL-FIA detection has been reported for ziram ${ }^{23}$, based on the chemiluminescence produced by the reaction of ziram with luminol in the presence of a catalyst. But this indirect CL method is more complicated and expensive and provided a higher limit of detection than the herein reported direct-CL method.

This paper reports a simple, rapid, sensitive and direct method for the determination of ziram and zineb, requiring no sophisticated equipment and fast enough for use in routine analyses, which are particularly suitable for environmental control. The proposed method is based on CL reaction between the photodegradated pesticides and Ce(IV) in an acidic medium by using quinine as sensitizer. It was successfully applied to the determination of ziram and zineb in water samples from different sources. The present method represent a great financial saving, compared with LC or GC techniques and a much better sensitivity than the reported spectrophotometric methods.

\section{Experimental}

\subsection{Reagents and stock solutions}

All experiments were carried out by using analytical reagent grade chemicals and Milli-Q water (Millipore, Bedford, MA, USA). The reagents used were: $\mathrm{KMnO}_{4}, \mathrm{~K} 3 \mathrm{Fe}(\mathrm{CN})_{6}, \mathrm{NaCl}, \mathrm{H}_{3} \mathrm{PO}_{4}$, acetone, and Triton X-100 from Panreac; $\mathrm{HNO}_{3}, \mathrm{HClO}_{4}, \mathrm{KIO}_{4}$ and $\mathrm{CeSO}_{4} \cdot 4 \mathrm{H}_{2} \mathrm{O}$ from Scharlau; $\mathrm{H}_{2} \mathrm{SO}_{4}, \mathrm{H}_{2} \mathrm{O}_{2}$, ethanol and acetonitrile from Merck; $\mathrm{NaOH}, \mathrm{HCl}, \mathrm{H}_{2} \mathrm{SO}_{4}$ and acetic acid from J.T. Baker; $\beta$-cyclodextrin, sodium dodecyl sulfate and hexadecylpyridinium chloride from Fluka and rhodamine B from Sigma. Cations tested as potential inorganic interferences were prepared from chloride $\left(\mathrm{Na}^{+}\right.$and $\mathrm{K}^{+}$(Panreac), $\mathrm{Ca}^{2+}$ (Probus), $\mathrm{Mg}^{2+}$ (Prolabo), $\mathrm{Zn}^{2+}$ (Scharlau), $\mathrm{Mn}^{2+}$ (D'Hernio)) 
or sulfate $\left(\mathrm{Cu}^{2+}\right.$ (Probus)) salts. Anions were obtained from sodium $\left(\mathrm{NO}_{2}^{-}\right.$(Probus), $\mathrm{SO}_{4}{ }^{2-}$ (Panreac), $\mathrm{HCO}_{3}{ }^{-}$(Guinama)) or potassium salts $\left(\mathrm{H}_{2} \mathrm{PO}_{4}{ }^{-}\right.$(Panreac) and $\mathrm{NO}_{3}{ }^{-}$(Probus)). Ziram $(97.0 \%)$ and Zineb $(71.50 \%)$ were supplied by Dr Ehrenstorfer. The chemicals tested as sensitizers were Rhodamine B (Merck), dioxane (Scharlau), 8-hydroxyquinoline (Merck), quinine hydrochloride (Sigma), sodium sulfite anhydrous (Panreac) and acridine orange (Sigma).

$100 \mathrm{mg} \mathrm{L}^{-1}$ stock solutions of ziram and zineb were prepared in $0.1 \mathrm{M} \mathrm{NaOH}$. In order to remove its impurities, it was necessary to filter zineb solutions by using polyamide membrane filters $(0.45 \mu \mathrm{m})$ (Sartorius). Both stock solutions were stored at room temperature in the dark. Ziram remained stable for at least 1 month, but the zineb solutions were unstable and hydrolyzed rapidly; because of that it was necessary to prepare them daily.

A $0.001 \mathrm{M} \mathrm{Ce}(\mathrm{IV})$ stock solution was prepared from cerium (IV) sulfate tetrahydrate (Scharlau) in $0.01 \mathrm{M}$ sulfuric acid weekly.

A 0.05 M quinine stock solution was prepared from quinine hydrochloride (Sigma) weekly.

The ion exchange resins used for sample treatment were Duolite C206A (Acros organics) (cationic) and IRA-400(OH) (Supelco) (anionic).

\subsection{Apparatus}

The flow manifold used is depicted in figure 2 and consisted of PTFE coil of $0.8 \mathrm{~mm}$ i.d.; a Gilson (Worthington, $\mathrm{OH}, \mathrm{USA}$ ), minipuls peristaltic pump provided with pump tubing from Omnifit; and a Model 161T031 valve (NResearch, Northboro, MA, USA). The photoreactor consisted of a $400 \mathrm{~cm}$ length and $0.8 \mathrm{~mm}$ i.d. PTFE tubing helically coiled around a $15 \mathrm{~W}$ low-pressure mercury lamp (Sylvania) for germicidal use. The flow cell was a flat-spiral quartz tube of $1 \mathrm{~mm}$ i.d. and $3 \mathrm{~cm}$ total diameter backed by a mirror for maximum light collection. The photodetector package was a P30CWAD5 type 9125B photomultiplier tube supplied by Electron Tubes; it was located in a laboratory-made light-tight box. The output was fed to a computer equipped with a counter-timer, also supplied by Electron Tubes.

When it was necessary channel 1 was splitted into two lines, one of which was used to test different photodegradation media. 


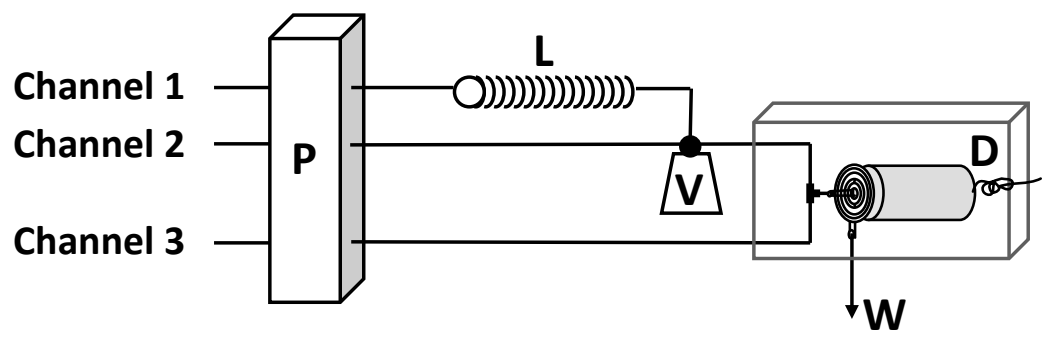

Channel 1: pesticide in $0.1 \mathrm{M} \mathrm{NaOH}\left(3.5 \mathrm{~mL} \mathrm{~min}^{-1}\right)$. Channel 2: $0.1 \mathrm{M} \mathrm{H}_{2} \mathrm{SO}_{4} / 0.001 \mathrm{M}$ quinine (7.5 $\left.\mathrm{mL} \mathrm{min}^{-1}\right)$. Channel 3: $3 \times 10^{-5} \mathrm{M}$ cerium (IV) $\left(7.5 \mathrm{~mL} \mathrm{~min}^{-1}\right)$. P: peristaltic pump. W: waste. D: detector. V: injection valve. L: lamp.

Figure 2. Schematic diagram for the optimized flow assembly.

\subsection{Sample preparation}

Water samples from different sources, namely: irrigation, ground and river waters, were freshly collected in plastic flasks and immediately filtered with polyamide membrane filters of $0.45 \mu \mathrm{m}$ to remove the suspended solid matter and stored in glass flasks protected from light at $4{ }^{\circ} \mathrm{C}$ in the refrigerator. They were used within one week. Prior to analysis, the water samples were spiked with 10 or $1 \mu \mathrm{g} \mathrm{mL}^{-1}$ ziram or $1 \mu \mathrm{g} \mathrm{mL}^{-1}$ zineb standard solutions, in order to obtain solutions containing 3 different pesticide concentrations $\left(0.8,0.08\right.$ and $0.04 \mu \mathrm{g} \mathrm{mL}^{-1}$ for ziram and $0.07,0.05$ and 0.02 $\mu \mathrm{g} \mathrm{mL}{ }^{-1}$ for zineb) in $0.1 \mathrm{M} \mathrm{NaOH}$.

\section{Results and discussion}

\subsection{Preliminary study}

By using the flow assembly depicted in figure 2, different oxidant systems, usually employed in methods based on direct chemiluminescence, were tested in order to obtain CL emission from ziram. The used oxidants were $10^{-3} \mathrm{M} \mathrm{KMnO}_{4}, \mathrm{Ce}(\mathrm{IV})$ and $\mathrm{KIO}_{4}$ in $0.5 \mathrm{M} \mathrm{H}_{2} \mathrm{SO}_{4}$ and $10^{-3} \mathrm{M} \mathrm{KIO}_{4}$, $\mathrm{H}_{2} \mathrm{O}_{2}$ and $\mathrm{K}_{3} \mathrm{Fe}(\mathrm{CN})_{6}$ in $1 \mathrm{M} \mathrm{NaOH}$. In this study a $100 \mathrm{mg} \mathrm{L}^{-1}$ ziram solution was mixed alternatively with $0.1 \mathrm{M} \mathrm{H}_{2} \mathrm{SO}_{4}, 0.1 \mathrm{M} \mathrm{NaOH}$ and water and the resulting mixture was propelled through a PTFE tube helically coiled around a UV lamp placed in-line and injected into a carrier of water. The carrier solution merged with the oxidant solution into a T-piece connected to the flowcell. Drug insertions were performed with and without previous irradiation. The obtained results are summarised in table 1 . 
Table 1. Effect of oxidizing agents on $100 \mu \mathrm{g} \cdot \mathrm{mL}^{-1}$ ziram CL.

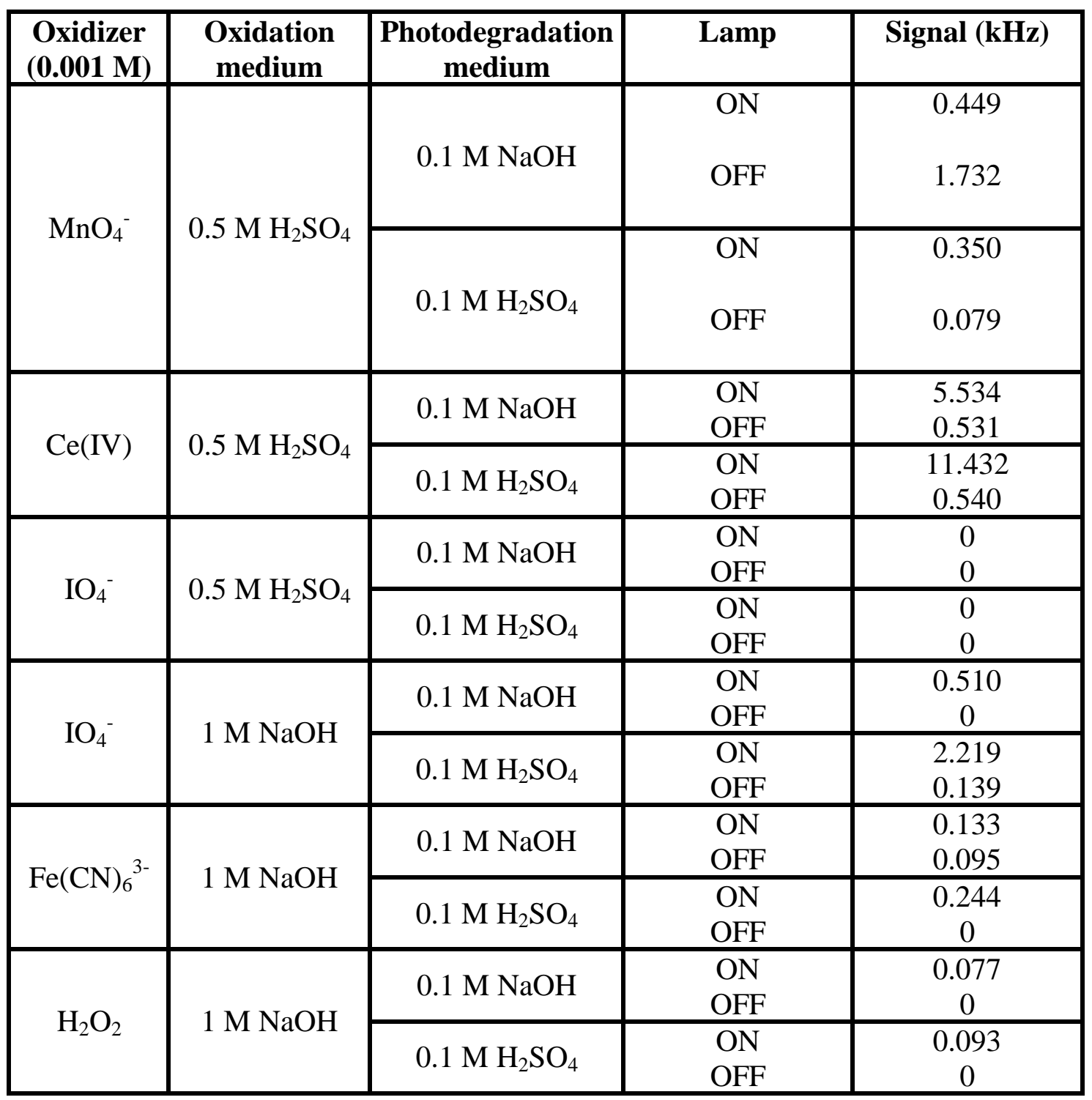

Based on these results, $\mathrm{Ce}(\mathrm{IV})$ and $\mathrm{KMnO}_{4}$ in $0.5 \mathrm{M} \mathrm{H}_{2} \mathrm{SO}_{4}$ together with $\mathrm{KIO}_{4}$ in $1 \mathrm{M} \mathrm{NaOH}$ were pre-selected for further study, because those oxidizing systems provided the highest CL signals. With those systems the experiment was repeated, but in that case a $20 \mu \mathrm{g} \mathrm{mL}^{-1}$ ziram solution was used and a range of oxidant concentrations was tested, namely: $\left(1 \times 10^{-5}-2 \times 10^{-3}\right) \mathrm{M}$ for cerium and permanganate and $\left(2 \times 10^{-3}-0.01\right) \mathrm{M}$ for metaperyodate. In all cases, except with permanganate, irradiation was employed, since it provided an increase in the signal, which suggested that a photofragment with improved CL features had been formed. The selected media for photolysis were acidic for metaperyodate, basic for permanganate and both media for cerium. Some of the obtained results are shown in figure 3. 


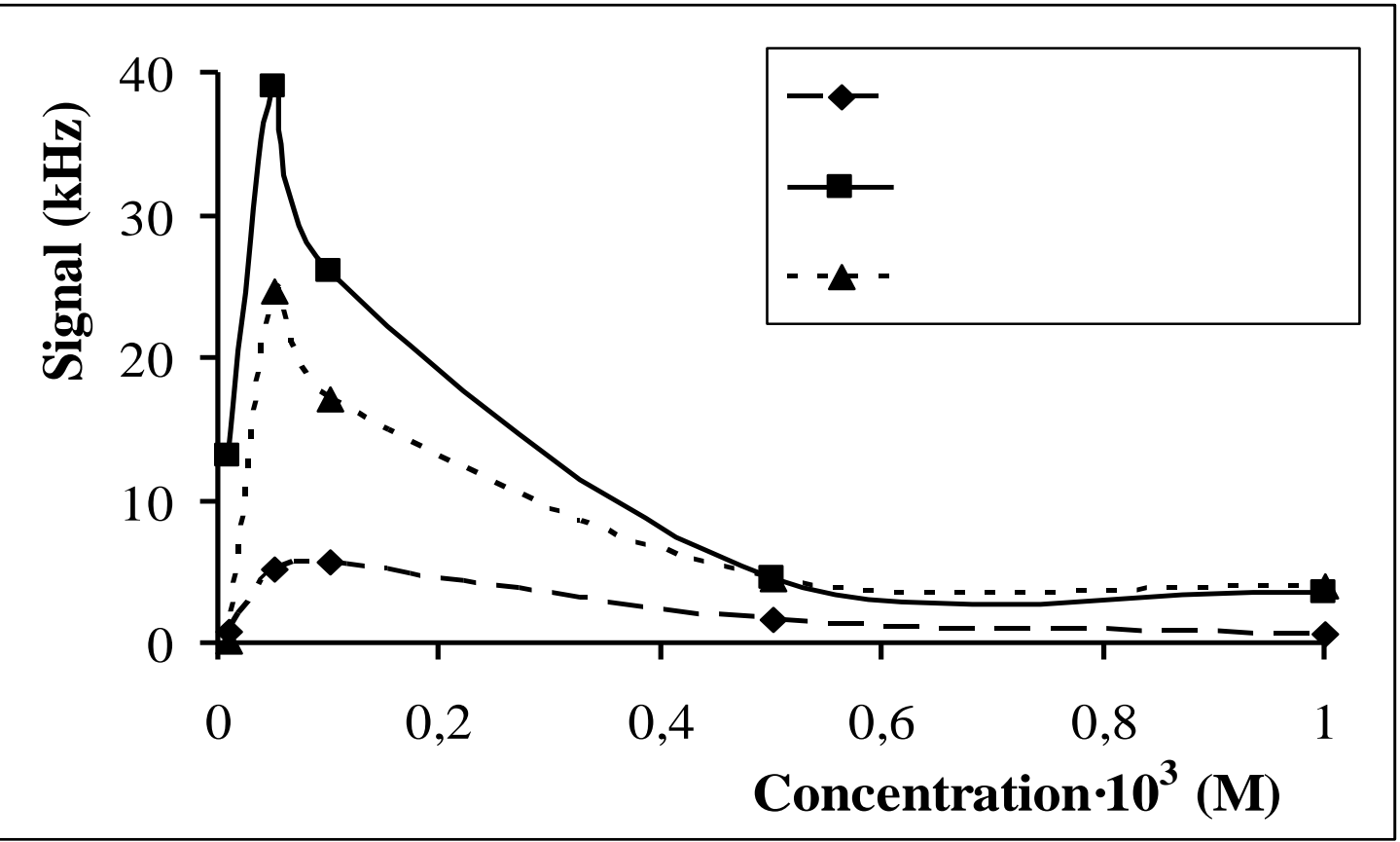

Figure 3. Effect of oxidizing agents on $20 \mu \mathrm{g} \cdot \mathrm{ml}^{-1}$ ziram $\mathrm{CL}$ (in brackets the used photodegradation media).

As can be observed in that figure, $\mathrm{Ce}(\mathrm{IV})$ provided a much higher CL-emission than $\mathrm{KMnO}_{4}$ over the whole range. The maximum emission intensity was reached at $5 \times 10^{-5} \mathrm{M}$ either in basic and acidic photodegradation media. When metaperyodate was used, the signal increased so do the concentration, but the maximum signal obtained was only $3.367 \mathrm{kHz}$, which is much lower than the highest signal provided by $\mathrm{Ce}(\mathrm{IV})$; because of it, this oxidant was discarded. With a view to improve the sensitivity of the method, Ce(IV) was selected as oxidizing agent and a value $5 \times 10^{-5} \mathrm{M}$ for its concentration was chosen for further study.

When Ce(IV) was used, the acidic and basic media provided similar results in the photodegradation step. In order to determine the best photodegradation medium, the effect of it was studied over the range (1-10) $\mu \mathrm{g} \mathrm{mL}^{-1}$ for ziram, which was alternatively mixed with $0.1 \mathrm{M} \mathrm{H}_{2} \mathrm{SO}_{4}, 0.1 \mathrm{M} \mathrm{NaOH}$ and water prior to the irradiation process. The obtained results were similar in the whole range of tested concentrations. From that fact was deduced that $\mathrm{pH}$ had no significant effect on the pesticide photolysis. Bearing in mind this fact and that dithiocarbamates decompose in acidic medium, but are stable in basic medium, this latter medium was finally chosen for the photodegradation of the pesticide. Because of that, it was unnecessary to put an additional channel to introduce the media, increasing in this way the sensitivity of the method by avoiding unnecessary dilutions. 


\subsection{Optimization of chemical and physical variables}

\subsubsection{Influence of the medium on the redox reaction}

The effect of sulfuric acid concentration (oxidation medium) added in carrier solution on $1 \mu \mathrm{g} \mathrm{mL}^{-1}$ ziram CL was studied over the range (0.05-1) M; the results are shown in figure 4.

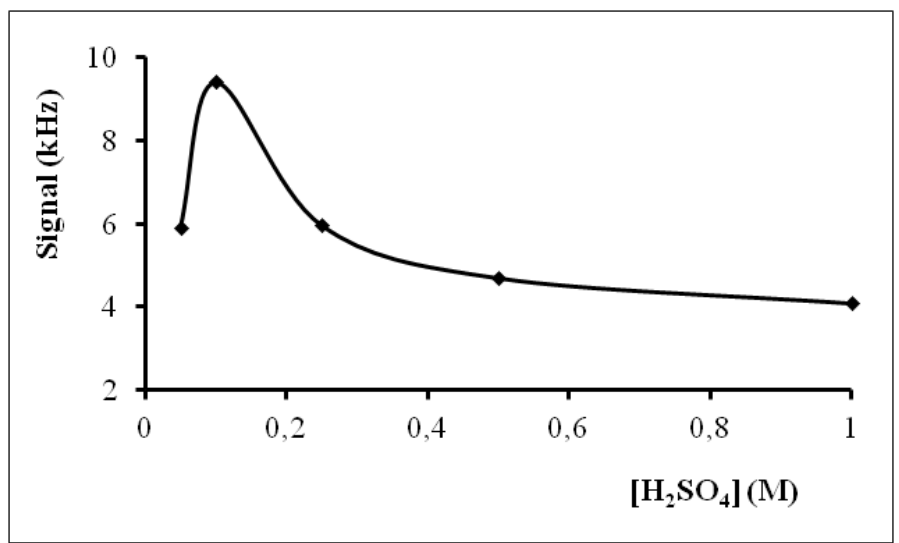

Figure 4. Effect of sulfuric acid on the CL ziram signal.

It is observed that as the acid concentration increases so do the signal up to $0.1 \mathrm{M}$ and above that concentration it decreased. Accordingly, a value of $0.1 \mathrm{M}$ for $\mathrm{H}_{2} \mathrm{SO}_{4}$ concentration was selected.

Other acids such as $\mathrm{HCl}, \mathrm{HNO}_{3}, \mathrm{CH}_{3} \mathrm{COOH}, \mathrm{H}_{3} \mathrm{PO}_{4}$ and $\mathrm{HClO}_{4}$ were also tested in the same conditions, but none of them provided better results. The best of those acids was $\mathrm{HClO}_{4}$ but the obtained signal was less than $50 \%$ of the emission intensity had been achieved with $\mathrm{H}_{2} \mathrm{SO}_{4}$. Hence this latter acid was finally adopted for subsequent testing.

Additionally, the effect of $\mathrm{NaOH}$ concentration in inserted ziram solutions was studied over the range $(0.01-0.2) \mathrm{mol} \mathrm{L}^{-1}$. The obtained results are shown in figure 5 .

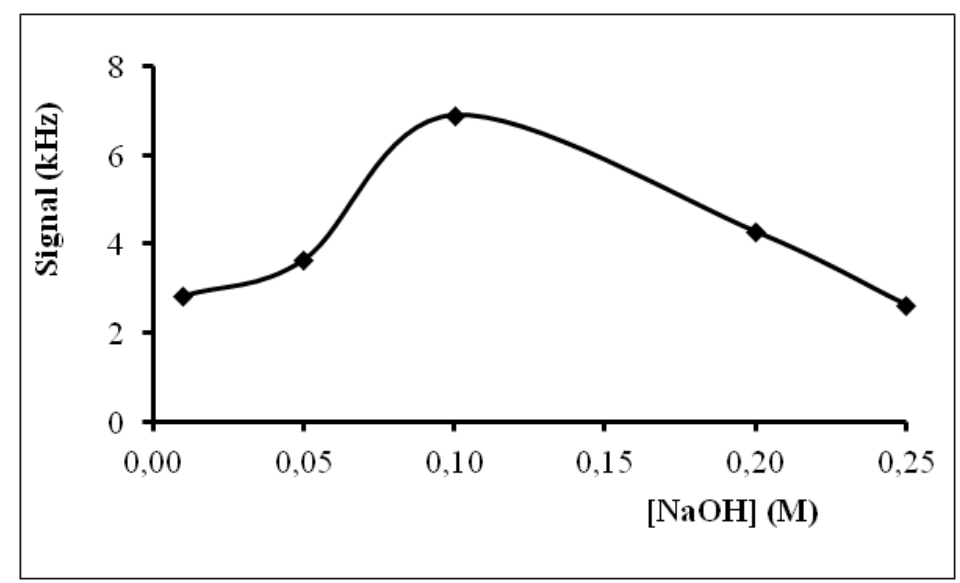

Figure 5. Effect of photodegradation media on the CL ziram signal.

The maximum was reached at $0.1 \mathrm{~mol} \mathrm{~L}^{-1}$, before and above this value the signal decreased slightly. Accordingly, this concentration was chosen for further work. 


\subsubsection{Effect of chemiluminescence enhancers}

Most CL reactions have low quantum efficiency and require the addition of a sensitizer. The influence of a variety of compounds that can act as enhancers in CL processes was studied by dissolving $5 \times 10^{-6} \mathrm{M}$ of them into the carrier stream. The tested substances were: quinine, rhodamine $\mathrm{B}$, sulfite, acridine orange and 8-hydroxyquinoline. Formic acid was also assayed but in this case a concentration of $1 \mathrm{M}$ was used. In all cases the CL signal of $1 \mu \mathrm{g} \mathrm{mL}^{-1}$ ziram decreased between 33 $\%$ (sulfite) and $93 \%$ (acridine orange and formic acid). Only with quinine a significant improvement ( $85 \%$ ) with regard to the obtained signal with no added enhancer was achieved. The influence of this sensitizer on the signal was examined over the range $(0.01-1) \times 10^{-4} \mathrm{M}$. The best improvements were achieved with $1 \times 10^{-4} \mathrm{M}(250 \%)$, consequently this concentration was chosen for further work.

Other reagents that have been used to promote the photodegradation of compounds, such as acetone $0.5 \%$, acetone $0.5 \%+$ acetonitrile $20 \%$, acetonitrile $20 \%$, ethanol $5 \%$ and dioxane $5 \%$, were also tested by adding them to a $1 \mu \mathrm{g} \mathrm{mL}^{-1}$ ziram solution prior to irradiation. In all cases a sharp decrease in the signal was yielded, because of that the use of these substances was discarded.

The effect of compounds providing organized media and structural rigidity to the medium, which can act increasing the lifetime of emitting species, was also investigated. To this end $2 \times 10^{-3} \mathrm{M}$ of $\mathrm{B}-$ cyclodextrin and the same concentration of anionic (SDS), cationic (hexadecylpiridium chloride) and $0.02 \%$ of neutral (Triton X-100) surfactants were included into the sample stream. However, the CL signal decreased more than $60 \%$ in all cases, consequently their use was rejected.

\subsubsection{Influence of the temperature}

The effect of the temperature on the redox reaction was studied by immersing the carrier and oxidant solutions in a thermostated bath at $20,30,40,50,60,70$ and $80{ }^{\circ} \mathrm{C}$. The influence of this parameter on the photodegradation was investigated identically, but immersing in this case the ziram solution in the bath. No significant influence of the temperature was observed in both cases. Subsequently room temperature was used for further work.

\subsubsection{Influence of the irradiation time}

The study of the effect of the irradiation time was carried out by changing the flow rate of $1 \mu \mathrm{g} \mathrm{mL}$ ${ }^{1}$ ziram solutions over the range $2-5 \mathrm{~mL} \mathrm{~min}^{-1}$ (which is equivalent to a $60-150 \mathrm{~s}$ range for the irradiation time). Only slight differences were observed. A value of $3.5 \mathrm{~mL} \mathrm{~min}^{-1}$ (105 s of irradiation) was selected for sample flow rate because the obtained signal was slightly higher and at the same time it was possible to achieve a high throughput. 


\subsubsection{Optimization of FIA parameters}

The FIA parameters and ranges studied were: total carrier and oxidant flow rates (4-18 $\left.\mathrm{mL} \mathrm{min}^{-1}\right)$, inserted sample volume $(100-400 \mu \mathrm{L})$ and the tube length from the injection valve to the detector $(50-90 \mathrm{~cm})$. The optimum values for those parameters were $15 \mathrm{~mL} \mathrm{~min}^{-1}, 300 \mu \mathrm{L}$ and $68 \mathrm{~cm}$ respectively.

\subsubsection{Re-optimization of chemical parameters}

Because of its special significance, oxidant and enhancer concentrations were re-optimized by using the new optimized values of hydrodynamic variables. The studied range for Ce (IV) was (1-7) $\times 10^{-5}$ $\mathrm{M}$, and three different concentrations, namely, $0.01,0.1$ and $1 \mathrm{mg} \mathrm{mL}^{-1}$ of ziram were tested for each oxidant concentration. The obtained results are shown in figure 6.

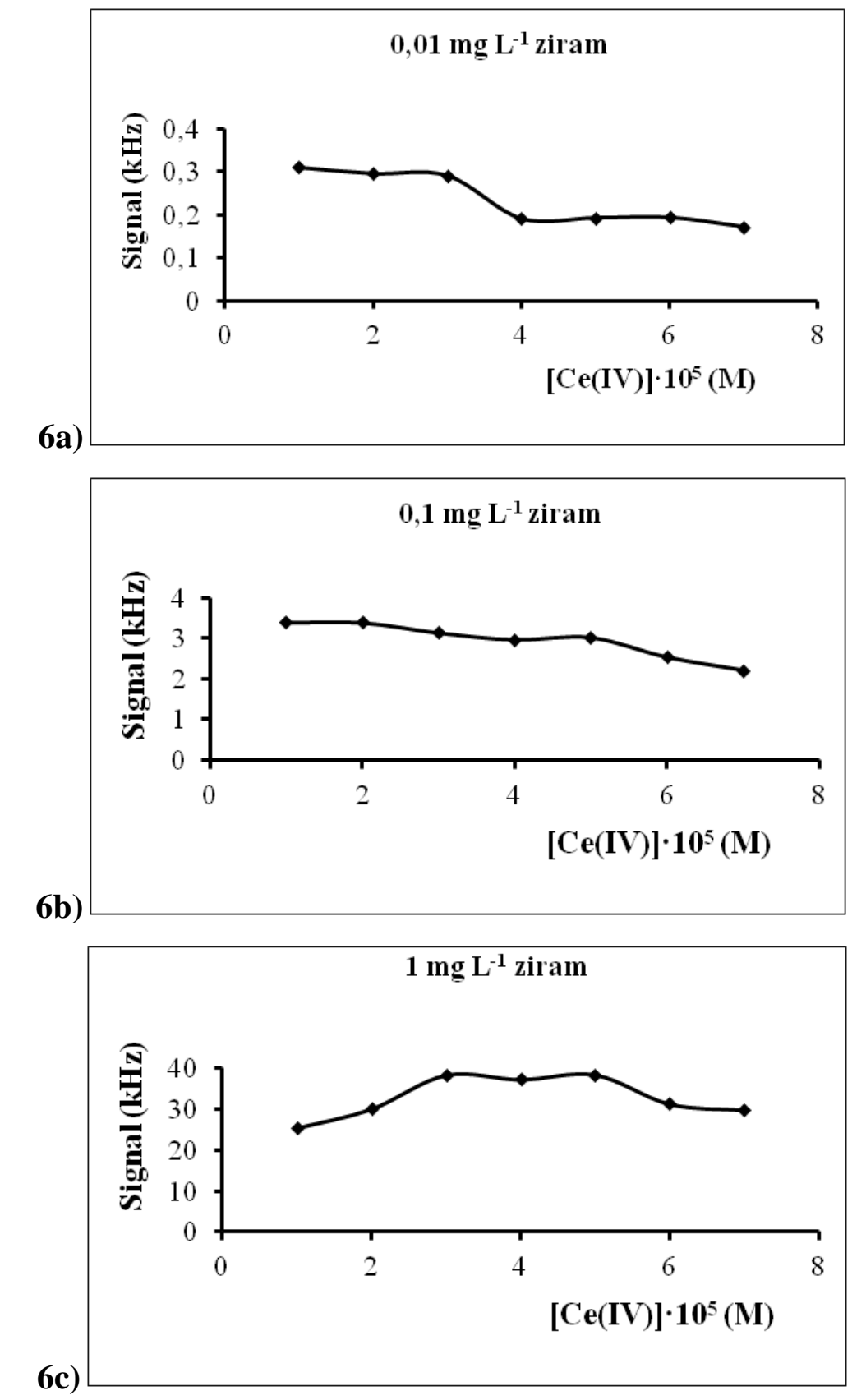

Figure 6. Effect of $\mathrm{Ce}(\mathrm{IV})$ concentration on the CL signal 
As shown in figure 6 a) the signal of $0.01 \mu \mathrm{g} \mathrm{mL}^{-1}$ ziram decreased for oxidant concentrations above $3 \times 10^{-5} \mathrm{M}$. In figure $6 \mathrm{~b}$ ) are depicted the obtained CL emissions for $0.1 \mu \mathrm{g} \mathrm{mL} \mathrm{m}^{-1}$ ziram, a slight decrease is observed when cerium concentration increased. Finally in figure $6 \mathrm{c}$ ) it can be observed a plateau over the (3-5) $\times 10^{-5} \mathrm{M}$ range. According to these results a value of $3 \times 10^{-5} \mathrm{M}$ was finally selected with a view to improve the sensitivity of the developed method, bearing in mind that for that concentration was obtained the best signal over three orders of magnitude.

Finally, quinine concentration was also re-optimizated. Its influence on the CL emission is illustrated in figure 7 . It was studied over the $(0.01-2) \times 10^{-3} \mathrm{M}$ range and as shown the signal increased as the quinine concentration increases up to $1 \times 10^{-3} \mathrm{M}$, above which the signal remained practically constant. A quinine concentration of $1 \times 10^{-3} \mathrm{M}$ was then chosen for further work.

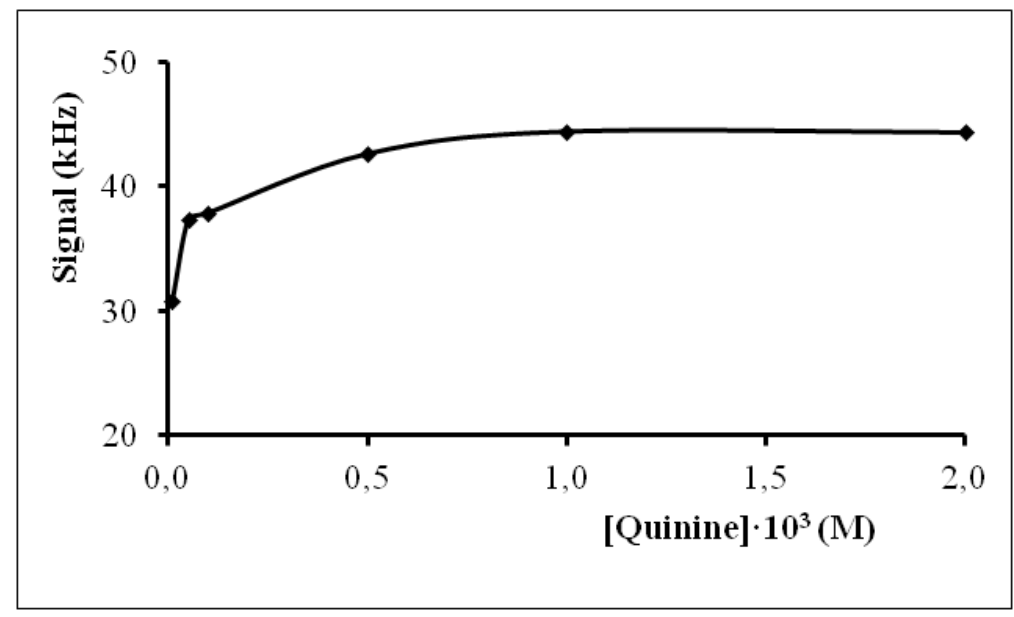

Figure 7. Effect of quinine concentration on the CL signal

\subsection{Method validation}

\subsubsection{Analytical characteristics}

Bearing in mind that zineb has a very similar chemical structure to ziram the optimized method was applied to the determination of both pesticides. The analytical figures of merit for ziram and zineb are summarised in table 2. 
Table 2. Analytical figures of merit for ziram and zineb determination.

\begin{tabular}{|c|c|c|}
\hline Analytical results & Ziram & Zineb \\
\hline $\begin{array}{c}\text { Linear equation } \\
\left(\mathrm{I}_{\mathrm{E}} \text { in KHz and } \mathrm{c} \text { in } \mu \mathrm{g} \mathrm{mL}^{-1}\right)\end{array}$ & $\mathrm{I}_{\mathrm{E}}=42.53 \mathrm{c}-0.016$ & $\mathrm{I}_{\mathrm{E}}=75.39 \mathrm{c}+0.055$ \\
\hline Dynamic range $\left(\mu \mathrm{g} \mathrm{mL}^{-1}\right)$ & $0.005-1$ & $0.005-0.2$ \\
\hline LOD $\left(\mathrm{ng} \mathrm{mL}^{-1}\right)$ & 1 & 101 \\
\hline Sample throughput $\left(\mathrm{h}^{-1}\right)$ & 121 & 1.2 \\
\hline Repeatability $(\%)(\mathrm{rsd})(\mathrm{n}=20)$ & 1.9 & 6 \\
\hline Reproducibility $(\%)(\mathrm{rsd})(\mathrm{n}=5)$ & 6.5 & \\
\hline
\end{tabular}

The calibration graph was constructed from seven concentrations and five replicates measurements for each. The limit of detection was taken to be the lowest pesticide concentration that yielded a signal equal to the blank signal plus three times its standard deviation. The repeatability of the proposed method was determined by analysing two series of 20 standard samples; one containing $0.5 \mu \mathrm{g} \mathrm{mL}^{-1}$ of ziram and the other $0.1 \mu \mathrm{g} \mathrm{mL} \mathrm{m}^{-1}$ of zineb. The day-to-day reproducibility was performed working in five different days with freshly prepared solutions (rsd was calculated for the slopes of the linear equations).

\subsubsection{Study of interferences}

The possible interference of the most common ions in water was investigated. This study was carried out by preparing solutions of salts containing these ions and pesticide in a concentration within the linear range of the developed method $\left(0.5\right.$ and $0.1 \mu \mathrm{g} \mathrm{mL}{ }^{-1}$ for ziram and zineb respectively). The obtained signals were tested against a pure solution of pesticide at the same concentration. A substance was considered not to interfere if it caused a relative error less than $5 \%$. The maximum tolerable concentrations $\left(\mu \mathrm{g} \mathrm{mL} \mathrm{m}^{-1}\right.$ ) for ziram and zineb determinations are shown on table 3 . 
Table 3. Influence of interfering compounds.

\begin{tabular}{|c|c|c|c|c|}
\hline Interference & [Interference]/[Ziram] & $\begin{array}{c}\text { Error for } \\
\text { ziram } \\
(\boldsymbol{\%})\end{array}$ & $\begin{array}{c}\text { [Interference]/[Zineb] } \\
\text { Error for } \\
\text { zineb } \\
(\%)\end{array}$ \\
\hline $\mathrm{Ca}^{2+}$ & 1000 & -0.5 & 1000 & -0.6 \\
$\mathrm{Mg}^{2+}$ & 100 & -4.4 & 100 & -4 \\
$\mathrm{Na}^{+}$ & 1000 & -3 & 1000 & -3.7 \\
$\mathrm{~K}^{+}$ & 1000 & -4.8 & 1000 & -0.7 \\
$\mathrm{NH}_{4}^{+}$ & 20 & -1.2 & 10 & 3.9 \\
$\mathrm{Cl}^{-}$ & 100 & -1.6 & 100 & -3.9 \\
$\mathrm{HCO}_{3}^{-}$ & 50 & -2 & 100 & -0.1 \\
$\mathrm{CO}_{3}^{2-}$ & 50 & -4.9 & 100 & 2.6 \\
$\mathrm{SO}_{4}^{2-}$ & 2000 & -4.3 & 2000 & 3.3 \\
$\mathrm{NO}_{3}^{-}$ & 100 & 0.7 & 20 & -2.2 \\
$\mathrm{HPO}_{4}{ }^{2-}$ & 10 & -1.2 & 4 & -1.8 \\
$\mathrm{H}_{2} \mathrm{PO}_{4}^{-}$ & 4 & -2 & 2 & -2.4 \\
\hline
\end{tabular}

\subsubsection{Applications}

The proposed method was applied to the determination of ziram and zineb in real samples. With this aim, two sets of three types of samples from different origins were selected: river, irrigation and ground waters; all of them were free of the studied pesticides. As different ions were found to interfere with the determination, they should be removed by passage through appropriate ionexchange resins: Duolite C206A (cationic) and IRA-400(OH) (anionic). The exchangers were prepared by packing Omnifit $15 \mathrm{~cm}$ x $3 \mathrm{~mm}$ i.d. glass columns with the resins.

One set of samples were spiked with 10 and $1 \mu \mathrm{g} \mathrm{mL} L^{-1}$ of ziram solutions before passing through the exchanger columns, in order to obtain values within the linear range of the method: $0.8,0.08$ and $0.04 \mu \mathrm{g} \mathrm{mL}^{-1}$ for each one of the three types of samples. With the other set of samples the followed procedure was the same, but in that case the three types of waters were spiked before passing the columns with a solution containing $1 \mu \mathrm{g} \mathrm{mL}^{-1}$ of zineb in order to achieve values within the linear range of that pesticide $\left(0.07,0.05\right.$ and $\left.0.02 \mu \mathrm{g} \mathrm{mL}^{-1}\right)$. The obtained results are shown on table 4 . 
Table 4. Origins and recoveries of the spiked water samples.

\begin{tabular}{|c|c|c|}
\hline Sample & Ziram recovery $(\boldsymbol{\%})$ & Zineb recovery $(\boldsymbol{\%})$ \\
\hline River & 95.1 & 95.3 \\
Irrigation water & 101.3 & 97.1 \\
Ground water & 99.4 & 99.4 \\
\hline
\end{tabular}

\section{Conclusions}

The proposed FIA-CL method is simple and economic. FIA methodology allows to use common reagents in small amounts, which decrease not only the cost of the analysis but its environmental impact. The high throughputs (more than 100 samples $\mathrm{h}^{-1}$ ) and low limits of detection $\left(1 \mathrm{ng} \mathrm{mL} \mathrm{m}^{-1}\right)$ achieved are especially suitable for routine analysis of environmental samples.

The method has been successfully applied to the analysis of ziram in water samples of different origins. It was possible also to carry out the determination of zineb in the same type of samples. This fact makes the developed method promising for the determination of another members of the dithiocarbamate family of pesticides.

\section{Acknowledgements}

The authors would like to thank Ministry of Education and Science from Spain and European Union for financial support: Project CTM2006-11991 and FEDER funds. 


\section{References}

[1] M. Lippmann (Ed.), Environmental toxicants: human exposures and their health effects, Wiley, USA, 2000.

[2] M. Marinovich, M.Guizzeti, F. Ghilardi, B. Viviani, E. Corsini and C.L. Galli, Arch. Toxicology, 71 (1997) 508.

[3] J. Goldman, M. Parrish, R. Cooper and W. McElroy, Reprod. Toxicol., 11 (1997) 185.

[4] K.Helrich., Official Methods of Analysis, AOAC International, Gettisburg, M.D., USA, $15^{\text {th }}$ edn, 1990, n 1217.

[5] G.W. Zhang, J.H Pan and Q.M. Que, Fenxi-Shiyanshi, 25 (2006) 27.

[6] S. Agarwal, S.G. Aggarwal and P. Singh, Talanta, 65 (2005) 104.

[7] S.K.Mehta, A.K.Malik, B.Singh and A.L.J.Rao, Talanta, 67 (2005) 725.

[8] A.K. Malik, V. Sharma, V.K. Sharma and A.L.J. Rao, J. Agric. Food Chem., 52 (2004) 7763.

[9] V.K. Sharma, J.S. Aulakh, S. Bansai, A.K. Malik and R.K. Mahajan, Int. J. Environ. Anal. Chem., 84 (2004) 1105.

[10] T. Kawamoto, M. Yano and N. Makihata, J. Chromatogr. A, 1074 (2005), 155.

[11] Z. Vryzas, E.N. Papadakis and E. Papadopoulou Mourkidou, J. Agric. Food Chem., 50 (2002) 2220.

[12] Y. Hanada, T. Tanizaki, M. Koga, H.Shiraishi and M. Soma, Anal. Sci., 18 (2002) 441.

[13] K.Y. Lin, J.H. Yen and Y.S. Wang, Food Sci. Agric. Chem., 3 (2001) 127.

[14] J. Hernández Borges, S. García, A. Cifuentes and M.A. Rodriguez Delgado, J. Sep. Sci., 27 (2004) 947.

[15] C. Mathieu, B. Herbreteau, M. Lafosse, P. Morin, M. Renaud, C. Cardinet and M. Dreux, J. High Resolut. Chromatogr., 23 (2000) 565.

[16] H. Van Lishaut and W.Schawck, J. AOAC Int., 83 (2000) 720.

[17] K. Yu, J. Krol and M. Balogh, Anal. Chem., 75 (2003) 4103.

[18] A.R. Turker and B. Sezer, Turk. J. Pharm. Sci., 2 (2005) 35.

[19] R.J. Casella, V.A. Salim, S. Garrigues, R.E.Santelli and M. de la Guardia, Anal. Sci., 18 (2002) 1253.

[20] S. Taguchi, A. Kakinuma and I. Kasahova, Anal. Sci., 18 (2002) 441.

[21] A. Malik and W. Faubel, Talanta, 52 (2000) 41.

[22] M.T. Pérez Pita, A.J. Reviejo, F.J. Manuel de Villena and J.M. Pingarrón, Anal. Chim. Acta, 340 (1997) 89.

[23] H. Kubo, Y. Tsuda, Y. Yoshimura, H. Homma and H. Nakazawa, Anal. Chim. Acta, 494 (2003) 49. 